\title{
Analysis of Physicochemical Properties of Bio-Oil from Hydrothermal Liquefaction of Blackcurrant Pomace
}

\author{
Suzanne Anouti, ${ }^{\dagger}$ Geert Haarlemmer, ${ }^{*}{ }^{\dagger}$ Maxime Déniel, ${ }^{\dagger, \dagger}$ and Anne Roubaud ${ }^{\dagger}$ \\ ${ }^{\dagger}$ CEA-LITEN, Laboratoire de Thermo-Conversion des Bioressources, 17 rue des Martyrs, 38054 Grenoble, France \\ ${ }^{\ddagger}$ Université de Toulouse, Ecole des Mines d'Albi, CNRS Centre RAPSODEE, 81013 Albi, France
}

\begin{abstract}
Bio-oils obtained from hydrothermal liquefaction of biomass are black viscous fuels with good heating values. This paper presents results of physical and chemical characterization of bio-oils produced by hydrothermal liquefaction of blackcurrant pomace. The oils are analyzed with standard normalized tests and compared to specifications required by commercialized biofuels and conventional fuels. Iodine value and total acid number are determined, showing relatively high values. GC/MS analysis demonstrates that bio-oil recovery by solvent extraction followed by subsequent evaporation of the solvent leads to the loss of some volatile compounds in the bio-oil. Thermogravimetric analysis are performed to study the volatility of HTL bio-oils, as well as to evaluate the carbon residue after evaporation. The viscosity of a bio-oil recovered by ethyl-acetate extraction was measured with a rotational viscometer at $25{ }^{\circ} \mathrm{C}$, leading to a viscosity of $1.7 \mathrm{~Pa} \cdot \mathrm{s}$. The results show furthermore that adding sodium hydroxide to the reaction medium has a limited influence on the properties of bio-oils. The choice of extraction solvent has conversely a significant influence on the quality of the produced oil. We demonstrate in this paper how standardized tests can be applied to hydrothermal bio-oils, to compare them with commercial fuels and evaluate the need for upgrading.
\end{abstract}

\section{INTRODUCTION}

Biomass is a generic term referring to materials derived from living, or recently living, organisms that include all organic matter of plant and animal origin. Typical examples of biomass are forestry and agricultural biomasses, food processing residues, algae, and sewage sludge. It is highly available worldwide and can be used as a source of renewable energy using biochemical or thermochemical processes. Studies on thermal conversion of biomass for biofuel production include works in gasification, ${ }^{1,2}$ pyrolysis, $^{3-5}$ and hydrothermal processes. ${ }^{6-9}$ Gasification and pyrolysis require dry biomass and need a drying step in the process. ${ }^{10}$ Hydrothermal processes convert wet feedstocks into renewable fuels and are very promising to save energy by avoiding drying of the biomass, as they use water as the reaction medium. $^{11}$

To convert wet biomass into bio-oil, hydrothermal liquefaction (HTL) uses the properties of subcritical water, that is very reactive at relatively high temperatures and pressures (250-370 ${ }^{\circ} \mathrm{C}$ and $\left.10-30 \mathrm{MPa}\right){ }^{6}$ The resulting products are generally organic, aqueous, and gaseous phases. The organic phase is often referred to as HTL raw (organic) residue or biocrude. It contains a liquid oily product (bio-oil) consisting of a complex mixture of compounds, a solid residue commonly known as char (insoluble in organic solvents) and a variable amount of water. The aqueous phase contains water-soluble products (acids, ketones, and other light polar compounds). The gaseous phase is particularly rich in $\mathrm{CO}_{2}$, and contains light hydrocarbons in small amounts. At the laboratory scale, the separation of the raw organic residue into bio-oil and char is generally carried out by extraction with an organic solvent, having ideally a similar polarity to that of target compounds contained in the bio-oil.

HTL bio-oils are complex mixtures containing a vast variety of oxygenated compounds of different molecular weights. ${ }^{11-13}$ Nitrogen-containing compounds are also common in bio- oils. $^{14,15}$ The bio-oil is dark in appearance and has a strong odor as well as low volatility and high viscosity. Various additives (mostly $\mathrm{pH}$ regulators) and catalysts influence the liquefaction reaction pathways and distribution of products. ${ }^{16}$

Bio-oils presented in the literature are most of the time characterized by their heating value and chemical composition. ${ }^{17}$ $\mathrm{Yin}^{17}$ reports bio-oils with average higher heating value of 35.5 $\mathrm{MJ} \cdot \mathrm{kg}^{-1}$ Hoffman at al. ${ }^{18}$ reports a heating value of $40.4 \mathrm{MJ} \cdot \mathrm{kg}^{-1}$ while Gan and Yuan ${ }^{19}$ report a heating value of $25.4 \mathrm{MJ} \cdot \mathrm{kg}^{-1}$. HTL bio-oils, even though extremely variable, are usually more calorific compared to other liquid fuels obtained from thermoconversion processes of biomass, like pyrolysis bio-oils. ${ }^{4}$ Typical oxygen content for HTL bio-oils is $15-20 \% .^{20,21}$ Many analytical techniques can be used to characterize the chemical nature of bio-oils. Gas Chromatography coupled with Mass Spectrometry (GC/MS) is the most frequently used method to analyze the composition of HTL bio-oils. ${ }^{13,16,22,23}$

Apart from the analyses cited above, few authors report functional fuel properties such as viscosity, density, volatility, and stability of HTL bio-oils. Some exceptions are Kumar and Pant ${ }^{24}$ and Wang at al. ${ }^{25}$ Such information is however important to identify potential applications as fuels. Each application is typically designed for a particular fuel. Inversely, most fuels target a particular application, with some crossover possibilities. There is a very large panel of standardized tests applied to commercially available fuels to assess their handling, storage, and combustion properties.

In this paper, we focus on hydrothermal liquefaction experiments of blackcurrant pomace. This resource is a representative of fruit and vegetable processing residue rich in 
fibers, with some proteins and lipids. The hydrothermal conversion of this resource (and fruit residues in general) has received little attention in the literature. ${ }^{11,26} \mathrm{We}$ report both experiments on the choice of solvents to recover bio-oil and on the use of sodium hydroxide as additive to modify the initial $\mathrm{pH}$ of the reaction mixture. Most studies looking at these factors in the liquefaction process concentrate on yields and sometimes in differences in chemical composition. ${ }^{23,27,28}$ No real investigation was done comparing the effect of extraction solvent or additives on the physicochemical properties of HTL bio-oils. Mazaheri et al. $^{29}$ compared different solvents like benzene, diethyl ether, and acetone used for recovering different oil fractions. Yang et al. ${ }^{30}$ investigated the extraction of chemical families from bio-oil using one or multistep extraction and comparing bio-oil yields of each solvent-extracted fraction. Valdez et al. ${ }^{23}$ present the extraction and analysis of bio-oils from microalgae with different solvents. These studies focus on yields and chemical compositions of the extracted bio-oils.

HTL bio-oil is not a commercially traded product and no clear applications have been identified yet. There are therefore no real standards for these oils to comply to. Most authors assume these oils are upgraded to diesel or fuel oil in an expensive catalytic upgrading process. ${ }^{31}$ Adapting the existing standards, the properties of the bio-oils can be easily compared with commercial fuels, which could direct their use toward certain applications. The objective of this paper is to apply a variety of classic analysis techniques related to storage, volatility, and combustion qualities. The values found will be compared to commercial fuels.

We tested various analysis techniques on five different bio-oils produced by HTL of blackcurrant pomace. The objective is to determine some physicochemical properties of HTL bio-oils by testing two methods developed for biodiesel, as well as to investigate the use of thermogravimetric analysis as an alternative method to evaluate the distillation behavior and to determine Conradson Carbon Number (CCR) values. The results allow the comparison of HTL bio-oils with commercial fuels (diesel, gasoline, heavy marine fuel oil). The influence of extraction solvents and $\mathrm{NaOH}$ as additive on bio-oil quality can be identified. We also shortly present the GC/MS results where we show the loss of some volatile compounds during the solvent evaporation step following bio-oil extraction.

\section{EXISTING STANDARDS FOR ANALYSIS OF FUELS AND BIOFUELS}

All commercial fuels have criteria related to storage. The iodine value (standard EN 14111 standard) is used in biodiesel characterization to evaluate the degree of unsaturation, due to the presence of unsaturated long chain fatty acids or their derivative compounds. The higher the iodine value, the more $\mathrm{C}=\mathrm{C}$ bonds are present. The presence of unsaturated compounds can lead to undesirable polymerization reactions during storage, decreasing fuel quality. Iodine value is therefore an indicator that could also be used to determine unsaturation in HTL bio-oils and also helpful to evaluate the storage potential. To our knowledge, no iodine value measurements have been performed on HTL bio-oils.

Another important quality measurement of petroleum crude oil and biodiesel to avoid corrosion risk to machinery and storage tanks is the total acid number, known as TAN (standards EN 14104 and ASTM D664). This measurement is often determined specifically to analyze biodiesel and pyrolysis oils, ${ }^{32,33}$ and could be applied to determine the acidity of HTL bio-oils. Wang et al. ${ }^{33}$ present the TAN of hydrothermal bio-oil from Litsea cubeba seeds, they found a value of $100 \mathrm{mg} \mathrm{KOH}$ per gram bio-oil.

Volatility and combustion properties are highly important when considering a liquid fuel quality. One of the main qualities is its heating value expressed in its Lower Heating Value (LHV) or Higher Heating Value (HHV) (standard NF EN 14918). Another major parameter is related to the volatility of the fuel. For storage purposes the product should be stable, and its vapor pressure expressed as the Reid Vapor Pressure (standard ASTM D323) should be inferior to a certain value (seasonal parameter). On the other hand, the boiling point distribution and the end of the distillation are also regulated (standard ASTM D86). Because HTL bio-oils produced in batch reactors are available in limited quantities, characterization by a full distillation curve is usually not possible. Other analysis techniques are then applied to understand the evaporation behavior of bio-oils. For instance, thermogravimetric analysis (TGA) can be applied to any type of sample that will undergo a mass change over time under the effect of temperature in a given atmosphere. The evaporation and thermal decomposition are part of the changes that are detected by thermogravimetry. ${ }^{16}$ TGA is often used to predict the thermal behavior of the major macromolecular components of biomass during their thermal conversion to biofuel. ${ }^{34}$ In other published works, TGA is used to simulate distillation or to show the volatility of products resulting from the biomass conversion. The distillation of different biodiesels produced from different vegetal oils are compared in term of percentage of weight loss at different temperatures. ${ }^{35}$ Comparison of volatilities of extracted fractions from HTL bio-oils obtained with different solvents are performed by TGA, showing the influence of solvent polarity on the extracted chemical groups from bio-oils. ${ }^{30}$

Fuels meant purely for combustion have more specifications related to combustion residues. These include soot-forming tendencies and Conradson carbon number (CCR, standards EN ISO 10370 and ASTM D4530). The standard CCR method is usually used to evaluate carbon residue from a fuel, which corresponds to the nondistillable residues that form after complete distillation. As well as for the evaporation behavior, TGA can also be used as an alternative method to the standard CCR method. ${ }^{36}$ Transportation fuels such as petrol, jet fuel and diesel have more narrow specifications in terms of combustion properties, for example, Research Octane Number (RON, standard ASTM D2699) and cetane number (standards EN ISO 5165 and ASTM D613). These latter two are of little interest for nonupgraded hydrothermal oils.

Viscosity of the fuel is another important parameter (standards EN ISO 3104 and ASTM D445). Viscosities of HTL bio-oils are rarely mentioned in the literature compared to pyrolysis bio-oils, but they are presented as highly viscous and semisolid liquids. High values were found between 8 and $1000 \mathrm{~Pa} \cdot \mathrm{s}^{20,37}$ Furthermore, according to Mohan et al., ${ }^{4}$ pyrolysis oils behave as a non-Newtonian fluid at low temperatures and in addition the viscosity increases in time due to aging. It is well agreed that rheological properties of bio-oils change over time. High storage temperatures are particularly unfavorable. This is due to many factors like polymerization, oxidation, and others. Studies on rheological properties and aging can be performed to give an indication of how viscosity of bio-oils change over time depending on temperature and storage conditions. ${ }^{32,38}$

\section{MATERIALS AND METHODS}

3.1. Materials and Resource Characterization. The experiments were performed using blackcurrant pomace supplied by a local 
manufacturer as the substrate. Table 1 gives the composition and Higher Heating Value (HHV) of the biomass used in this study. Blackcurrant

Table 1. Composition and HHV of Blackcurrant Pomace ${ }^{a}$

$\begin{array}{ll} & \text { blackcurrant pomace } \\ \text { moisture content (wt \%) } & 59.6 \\ \text { fiber content (wt \% dry matter) } & \\ \text { NDF } & 61.7 \\ \text { ADF } & 52.8 \\ \text { ADL } & 35.4 \\ \text { proteins (wt \% dry matter) } & 16.9 \\ \text { lipids (wt \% dry matter) } & 3.5 \\ \text { ash content at } 550^{\circ} \mathrm{C}(\text { wt \% dry matter) } & 4.5 \\ \text { elemental composition (wt \% dry matter) } & \\ \text { C } & 50.3 \\ \text { H } & 6.8 \\ \text { O } & 36.8 \\ \text { N } & 1.9 \\ \text { S } & 0.2 \\ \text { HHV }\left(\mathrm{MJ}^{\circ} \mathrm{kg}^{-1}\right) & 18.51\end{array}$

${ }^{a}$ NDF: Neutral Detergent Fibers; ADF: Acid Detergent Fibers; ADL: Acid Detergent Lignin; HHV: Higher Heating Value.

pomace is a residue from berry pressing, mainly constituted by seeds and peels: it is a wet and fiber-rich biomass, also containing a non-negligible amount of proteins and a small amount of lipids.

For each HTL experiment, distilled water was used. Pellets of Sodium Hydroxide $\mathrm{NaOH}$ were purchased from Merck and used as received. Ethyl-acetate, isopropyl alcohol, acetone, and hexane were purchased from Sigma-Aldrich and used as received. In our experiments, all the reagents were analytical grade.

3.2. Production of Bio-Oil by HTL of Blackcurrant Pomace. Hydrothermal liquefaction experiments were performed in a $0.6 \mathrm{~L}$ stainless steel (SS316) stirred batch reactor (Parr Instruments Company). In a typical experiment, the reactor is filled with approximately $240 \mathrm{~g}$ of biomass slurry prepared from blackcurrant pomace and distilled water at a constant $14 \mathrm{wt} \%$ dry matter to water ratio. In some cases, sodium hydroxide is added as an additive. The autoclave is leak tested, purged and pressurized to $1 \mathrm{MPa}$ with nitrogen gas, to ensure sufficient pressure for gas analysis after the reaction. The pressure inside the reactor is a function of the reaction temperature, the amount of water, and the amount of produced gas during the process. The reactor is stirred at $600 \mathrm{rpm}$ and is heated to the reaction temperature in about $35 \mathrm{~min}$. Once the reactor reaches the reaction temperature, it is held during a specified time within $\pm 1{ }^{\circ} \mathrm{C}$ of the specified operating temperature (holding time). For these experiments, a $60 \mathrm{~min}$ holding time is applied. After the holding time, the reactor is rapidly cooled to room temperature in $20 \mathrm{~min}$ by an air quench.

After venting the reactor for gas analysis, the content of the reactor is first filtered on a Buchner filter to separate the aqueous phase from the raw organic residue. The raw organic residue is sticky, and removed from the reactor as best as possible. The reactor is then weighed, and the weight difference with the empty reactor is counted as raw organic residue. The raw organic residue is dried at room temperature under air circulation until a stable mass was obtained.
The raw residue is extracted with a solvent, using a 10-fold amount of solvent to separate the bio-oil from the char. Bio-oil is recovered after evaporation of the solvent at room temperature under air circulation, until a stable weight is obtained. It is assumed that no residual solvent is left in the bio-oil. The char is also dried at room temperature under air circulation, until a stable weight is obtained. Weight loss of the char after extraction and drying is used to determine the proportion of solventsoluble organics in the raw residue, and therefore the bio-oil yield. All yields reported in this study are expressed in weight percentage of the dry biomass (wt \% DM).

3.3. Physicochemical Properties. A wide variety of tests are available, many subject to strict standards.

Total Acid Number (TAN) and lodine Value. The total acid number (TAN) and the iodine value are determined according to European standards EN 14104 and EN 14111, respectively. These standards have been defined for the fatty acid methyl esters FAME of Biodiesel. The procedures followed in this paper are adapted to be able to use color indicators even when the oil is black. Both TAN and iodine value measurements were repeated three times for each sample.

Total acid number (TAN) is the number of milligrams of potassium hydroxide $\mathrm{KOH}$ required to neutralize the acidic functions present in one gram of oil. It is expressed in mg $\mathrm{KOH}$ per gram of the sample. To determine the TAN value, $50 \mathrm{mg}$ of bio-oil sample was dissolved in 10 $\mathrm{mL}$ of isopropyl alcohol and then titrated by a $20 \mathrm{mM} \mathrm{KOH}$ solution, using Phenolphthalein as a color indicator. The concentrations of bio-oil in isopropyl alcohol must be kept low to guarantee a certain transparency and good solubility of nonpolar compounds.

Iodine value is the mass of halogen binding to double-bonds contained in $100 \mathrm{~g}$ of bio-oil. It is expressed in grams of iodine $\left(\mathrm{I}_{2}\right)$ per $100 \mathrm{~g}$ of the sample, according to the standard EN 14111. It is based on the reaction between a Wijs ( $\mathrm{ICl}$ ) solution and the double-bonds contained in compounds of the bio-oil. Excess of the Wijs reagent becomes $\mathrm{I}_{2}$ by adding potassium iodide $\mathrm{KI}$. The concentration of formed iodine $\mathrm{I}_{2}$ is then determined by titration with sodium thiosulfate. Bio-oil samples of 90-100 mg were used for iodine value measurements.

GC/MS Analysis. GC/MS (gas chromatography/mass spectroscopy) analysis of bio-oil was performed in Clarus 500/600S PerkinElmer apparatus. The column used is a DB-1701 capillary column $60 \mathrm{~m} \times 0.25$ $\mathrm{mm}, 0.25 \mu \mathrm{m}$ film thickness. The injection of $1 \mu \mathrm{L}$ of bio-oil samples is performed on Split mode 10:1 with Helium as carrier gas. The injector temperature is maintained at $250{ }^{\circ} \mathrm{C}$. The GC oven temperature is programmed from $45^{\circ} \mathrm{C}(10 \mathrm{~min})$ to $230^{\circ} \mathrm{C}$ at a rate of $6{ }^{\circ} \mathrm{C} \cdot \mathrm{min}^{-1}$, and held at $230^{\circ} \mathrm{C}$ during $9.17 \mathrm{~min}$. It is then raised to $250^{\circ} \mathrm{C}$ at a rate of 10 ${ }^{\circ} \mathrm{C} \cdot \mathrm{min}^{-1}$, held at $250^{\circ} \mathrm{C}$ during $20 \mathrm{~min}$. The transfer interface and the ion source in the mass spectrometer are maintained at $230^{\circ} \mathrm{C}$. Bio-oil samples dissolved in ethyl acetate are filtered with a $0.45 \mu \mathrm{m}$ PTFE filter before analysis. The National Institute of Standards and Technology (NIST) mass spectral library is used to identify the compounds.

Thermogravimetric Analysis. (TGA) was conducted on a SETSYS SETARAM instrument, using platinum crucibles to carry bio-oil samples. Bio-oil samples of approximately 5 to $6 \mathrm{mg}$ were used. The oven temperature was first risen from 35 to $900{ }^{\circ} \mathrm{C}$ at a heating rate of 10 ${ }^{\circ} \mathrm{C} \cdot \mathrm{min}^{-1}$, under a $50 \mathrm{~mL} \cdot \mathrm{min}^{-1}$ nitrogen flow. Temperature was then held for $10 \mathrm{~min}$ at $900{ }^{\circ} \mathrm{C}$ under a $50 \mathrm{~mL} \cdot \mathrm{min}^{-1}$ air flow to perform the combustion stage.

Viscosity Measurements. The dynamic viscosity of bio-oil is measured using a rotational viscometer at different temperatures. The viscometer is supplied by Sheen, composed of a sample cell placed in a thermostat adapter and a range of different cylindrical spindles. A sample

Table 2. Yields Obtained from Liquefaction and Extraction Experiments

\begin{tabular}{|c|c|c|c|c|c|c|c|}
\hline id oil & solvent used & initial $\mathrm{pH}$ & oil yield & carbon content oil & $\mathrm{HHV}(\mathrm{MJ} / \mathrm{kg})$ & TAN (mg KOH/g oil) & iodine value $\left(\mathrm{g} \mathrm{I}_{2} / 100 \mathrm{~g}\right.$ oil \\
\hline L1 - EA & ethyl acetate & 3.2 & $28( \pm 3) \%$ & $75( \pm 1) \%$ & 33.4 & 134 & 150 \\
\hline L2 - HEX & hexane & 3.2 & $17( \pm 3) \%$ & $80( \pm 1) \%$ & 38.4 & 159 & 117 \\
\hline L3 - ACET & acetone & 3.2 & $32( \pm 3) \%$ & $74( \pm 1) \%$ & 35.0 & 134 & 131 \\
\hline L4 - ISOP & isopropyl alcohol & 3.2 & $29( \pm 3) \%$ & $73( \pm 1) \%$ & 34.6 & 137 & 118 \\
\hline L5 NaOH - EA & ethyl acetate & $13(\mathrm{NaOH})$ & $33( \pm 3) \%$ & $69( \pm 1) \%$ & 35.5 & 108 & 149 \\
\hline
\end{tabular}


volume between 8 and $11 \mathrm{~mL}$ (depending on the viscosity of the liquid) is used. Viscosity is determined by measuring the torque required to rotate the spindle at the required frequency.

Other Analysis. The higher heating value HHV $\left(\mathrm{MJ} \cdot \mathrm{kg}^{-1}\right)$ of bio-oils is measured using a Parr 6200 bomb calorimeter (Parr Instruments Company). The organic carbon content of the bio-oils is determined by a total organic carbon analyzer (Shimadzu SSM-5000A). Density is determined by letting a droplet of the bio-oil float in distilled water. By adding ethanol under constant stirring, the density of the aqueous phase is progressively lowered until the droplet begins to sink. The density of the water is then measured by weighing a determined volume in a graduated cylinder. ${ }^{39}$ This method allows the density measure of very small volumes.

\section{RESULTS}

4.1. Bio-Oil Yields. In Table 2, we present the results obtained from the liquefaction experiments. The experiments were performed at $300{ }^{\circ} \mathrm{C}$. Holding time was $60 \mathrm{~min}$. The experiments deal with variations in the extraction solvent and the addition of sodium hydroxide in the initial mixture. From the results, it appears that increasing the initial $\mathrm{pH}$ is favorable to the bio-oil yield. The calorific value of the bio-oils are all comparable, except for the oil obtained with hexane. The oil obtained with hexane is of a higher quality: it has a higher heating value and carbon content but shows a much lower yield.

The water content of the extracted bio-oils is typically less than $1 \%$ and it is not further discussed in this paper. The specific gravity of the bio-oil varies from 0.96 (L5) to 0.99 (L4).

4.2. Viscosity. Due to the limited capacity of the autoclave reactor and the recovery procedure, most samples were available in small quantities. The viscosity measurement requires a large volume that was not available for most samples. The ethyl acetate extracted bio-oil without additives (sample L1-EA) was the only analyzed bio-oil. The evolution of the dynamic viscosity as a function of the temperature is presented in Figure 1. At low temperatures, the oil is free-flowing but highly viscous. With increasing temperatures, the viscosity decreases rapidly.

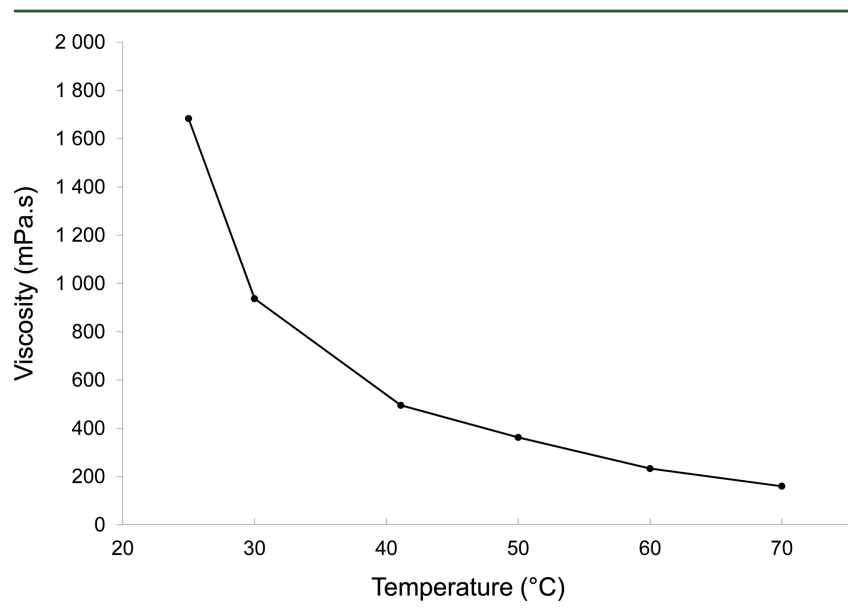

Figure 1. Evolution of the viscosity of bio-oil L1-EA from hydrothermal liquefaction of blackcurrant pomace.

4.3. Total Acid Number (TAN) and lodine Value. Total acid number (TAN) and iodine value for the studied bio-oils are presented in Table 2. The TAN values are much higher than those specified in standards for commercial fuel and biodiesel (typically TAN $\leq 0.5 \mathrm{mg} \mathrm{KOH} \mathrm{g}^{-1}$ ). The acidity of these bio-oils is probably related to the presence of long-chain fatty acids, carboxylate and phenolic compounds. Phenolic compounds usually have $\mathrm{p} K_{\mathrm{a}}$ values between 9 and 10 . They can therefore be titrated by a $20 \mathrm{mM} \mathrm{KOH}$ solution ( $\mathrm{pH}$ around 12 ) as validated in the text of the ASTM D664 standard. Note that the bio-oil extracted with hexane has the highest TAN value $(159 \mathrm{mg} \mathrm{KOH}$ $\left.\mathrm{g}^{-1}\right)$.

The results of iodine value measurements show that the highest iodine values are obtained for ethyl-acetate extracted biooils. The fact that iodine values are generally very high suggests that this titration is neither selective nor dedicated toward double bonds in linear fatty acid chains. The double bonds in substituents of aromatic derivatives and other cyclic compounds may also be titrated. The proportions of the TAN and iodine values due to fatty acids, relative to other compounds, has not been determined.

4.4. GC/MS Analysis. Bio-oil is obtained by solvent extraction from a raw organic residue followed by subsequent evaporation of the solvent. This evaporation step has an influence on the chemical composition of the bio-oil, as illustrated in Figure 2. In fact, it compares GC-MS analysis of a bio-oil prior to

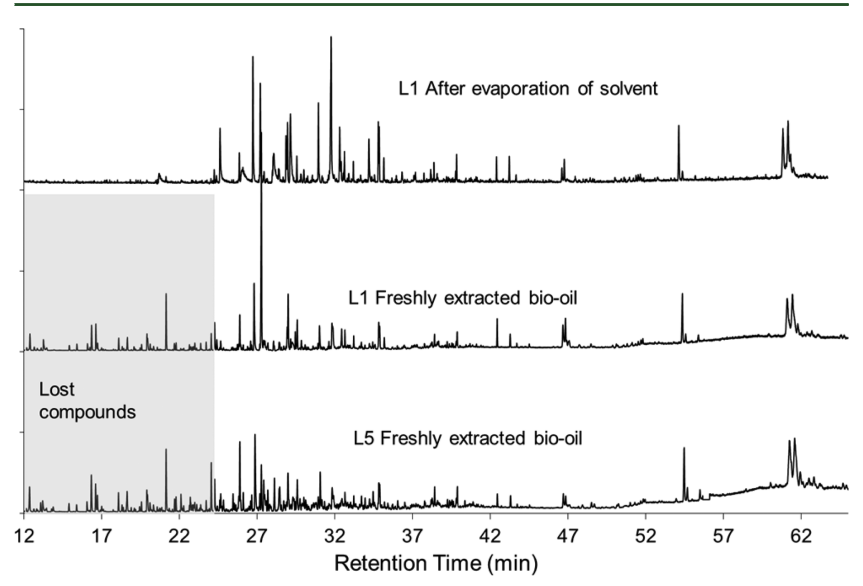

Figure 2. Chromatograms of extracted and resolubilized bio-oil after evaporation of the solvent.

solvent evaporation, and the same bio-oil after solvent evaporation and redissolution in the same solvent. In this case, ethyl-acetate was used to perform solvent extraction.

From these chromatograms, it can be observed that solvent evaporation causes the loss of many light components, corresponding to retention times between 12 and $24 \mathrm{~min}$. Figure 3 gives a more precise overview of the volatile compounds that are lost: 20 volatile compounds were positively identified in this nonevaporated bio-oil when analyzed without any dilution in GC/MS. Those molecules are not recovered after evaporation. This is confirmed when zooming in on a part of the chromatogram up to $25 \mathrm{~min}$. This zoom is presented in Figure 3. In the same Figure 2, we also show the chromatogram of the bio-oil produced in basic conditions (L5). It is clear that both biooils are relatively close in chemical composition of the more volatile components. Some peaks of mainly phenolic components are reduced, due to better solubilization in aqueous phase of phenol monomers and dimers at high $\mathrm{pH}$ values.

The compounds identified in Figure 3 are listed in Table 3. Heavier compounds are evaporated to a smaller extent and are relatively unaltered.

The nature of the solvents also has an influence on the chemical composition of the bio-oil. Figure 4 shows the chromatograms of bio-oils extracted from the same raw organic residue with four different solvents ( $\mathrm{L} 1$ to $\mathrm{L} 4$ ). The main 


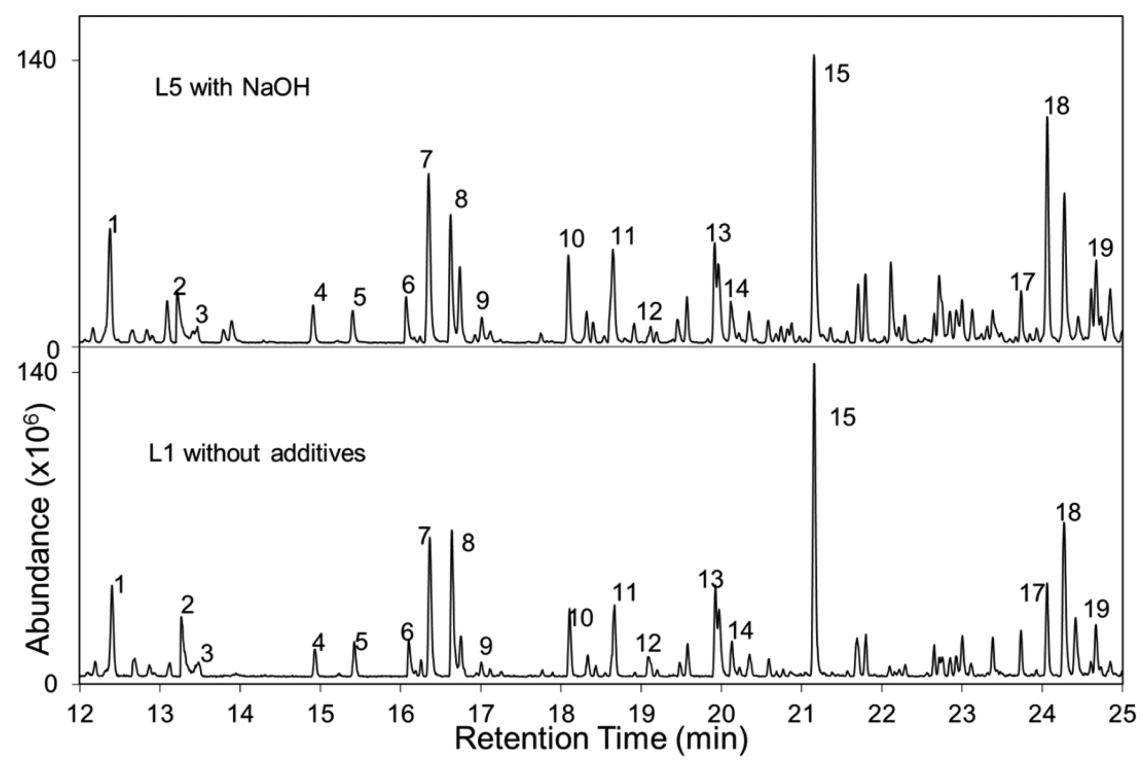

Figure 3. Volatile compounds identified by GC/MS analysis in ethyl-acetate extracted bio-oil (before evaporation of the solvent).

Table 3. Identified Volatile Compounds in Bio-Oil (using the NIST Spectra Database Match)

$\begin{array}{lll}\text { toluene } & 11 & \text { cyclopentanone, 3-methyl- } \\ \text { pyrazine } & 12 & \text { 2-cyclopenten-1-one } \\ \text { pyridine } & 13 & \text { pyrazine, 2,5-dimethyl- } \\ \text { 3-hexanone } & 14 & \text { pyrimidine, 2,5-dimethyl- } \\ \text { 2-hexanone } & 15 & \text { ethyl-pyrazine } \\ \text { pyridine 2-methyl- } & 16 & \text { cyclopenten-1-one, 2-methyl-2- } \\ \text { cyclopentanone } & 17 & \text { cyclopenten-1-one, 2,3-dimethyl-2- } \\ \text { pyrazine, methyl- } & 18 & \text { cyclopenten-1-one, 3-methyl-2- } \\ \text { ethylbenzene } & 19 & \text { cyclopenten-1-one, 3,4-dimethyl-2- }\end{array}$

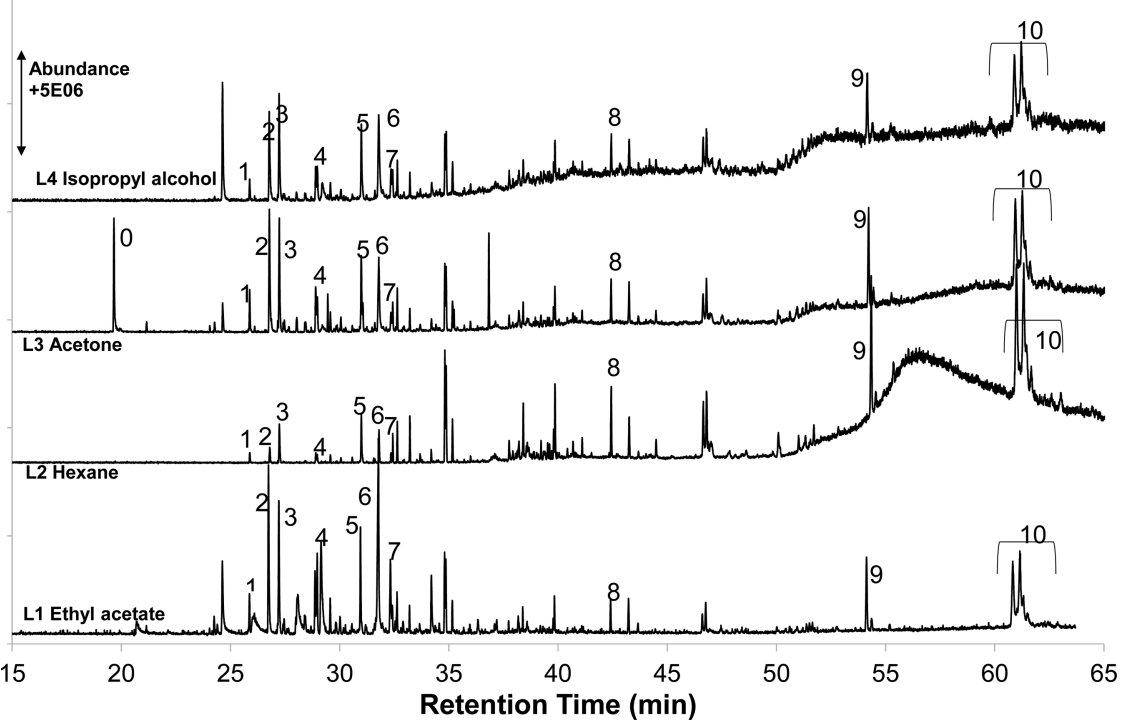

Figure 4. Chromatograms of oil extracted with different solvents.

identified compounds are presented in Table 4, only positive identifications are presented. In practice, due to the abundancy of the compounds there are many overlaying peaks, making positive identification delicate. The chromatograms show that these four bio-oils are mostly alike except for bio-oil extracted with hexane (L2), which contains fewer identified compounds. The broad peak (10) detected at $58 \mathrm{~min}$ corresponds to fatty acids derivatives.

As for the bio-oil extracted with ethyl-acetate (L1), the identified peaks in GC/MS are similar to the acetone extracted bio-oil (L3). However, we note that ethyl-acetate extracted biooil (L1) contains other peaks (having a relative area percentage 
Table 4. Identified Compounds in Extracted Bio-Oils with Four Different Solvents

\begin{tabular}{|c|c|c|c|}
\hline 0 & 2-pentanone -4-hydroxy -4-methyl & 6 & $\begin{array}{l}\text { 2-hydroxypyridine-4- } \\
\text { carboxaldehyde }\end{array}$ \\
\hline 1 & 2-cyclopenten-1-one, 2,3-dimethyl- & 7 & $\begin{array}{l}\text { 2-hydroxypyridine-4-ethyl } \\
\text { ketone }\end{array}$ \\
\hline 2 & phenol & 8 & $\begin{array}{l}\text { hexadecanoic acid, methyl } \\
\text { ester }\end{array}$ \\
\hline 3 & guaiacol & 9 & $\begin{array}{l}\text { dodecanamide derivative } \\
\text { with double bond }\end{array}$ \\
\hline 4 & phenol, 4-methyl- & 10 & $\begin{array}{l}\text { octadecadieanamide } \\
\text { derivatives ( } \mathrm{C} 18 \text { double } \\
\text { bond) }\end{array}$ \\
\hline & phenol, 4-ethyl- & & \\
\hline
\end{tabular}

$\geq 3 \%$ ) nonidentified by the NIST database and absent in other bio-oils. The highest bio-oil yield was obtained by using acetone to perform the extraction. These abundant unknown peaks confirm that ethyl acetate is a powerful extraction solvent with high affinity to diverse compounds, more than the three others tested solvents.

We mention also that low-boiling-point compounds with a phenol ring structure are characteristic of these bio-oils, in particular phenol and guaiacol (2-methoxyphenol). At higher retention times, heavier compounds corresponding to lipid derivatives - among them fatty acid methyl esters and long-chain amides - and potential oligomeric structures are detected.

4.5. Thermogravimetric Analysis. In this section, we present results of the thermogravimetric analysis (TGA) of the extracted bio-oils. The percentage of weight loss of the bio-oils at $250{ }^{\circ} \mathrm{C}$ on $\mathrm{TG}$ curves can be an indication to evaluate the proportion of the bio-oil that is not analyzed by GC/MS. TGA analysis also allows comparing the volatility of the studied biooils and of some well-known commercial fuels.

Figure 5 and Figure 6, respectively, present the TG (thermogravimetric) and the DTG (differential thermogravimetric) curves, showing the percentage and the rate of weight loss versus the temperature. In Figure 5, the heavy Iraqi crude, diesel, light cycle oil and heavy gas oil TG curves are reproduced from the literature. ${ }^{40-42}$ These curves are produced at the same heating rate $\left(10^{\circ} \mathrm{C} \cdot \mathrm{min}^{-1}\right)$ under nitrogen atmosphere. They are presented here as references for comparison purposes with the studied bio-oils (L1-L5). From Figure 5, it can be seen that hydrothermal oils are situated in the light end of the heavy refinery streams and are not dissimilar to heavy crude oil. They are, however, generally much heavier than diesel fuel. TG and DTG curves are very similar for most oils, except for the one recovered by extraction with hexane (L2). This was also observed by GC/MS analysis in section 4.4, underlining the importance of solvent polarity. Most polar solvents produce oil with similar evaporation behavior, even when very basic hydrothermal conditions are used (sample L5).

TG analysis shows also the presence of residual solvent left after evaporation in the recovered bio-oil, as in the case of isopropyl alcohol and acetone extracted bio-oils. This is confirmed by GC/MS analysis where total ion chromatograms present peaks of these two solvents in their corresponding biooils. These solvents are less volatile than ethyl-acetate, which evaporates more rapidly at ambient conditions.

From the DTG curves on Figure 6, several temperature zones can be identified. Each zone is more or less significant, depending on its content in volatiles. Peaks on DTG curves observed at 100 ${ }^{\circ} \mathrm{C}$ correspond to the evaporation of compounds having a boiling point near or less than $100{ }^{\circ} \mathrm{C}$, as well as residual extraction solvent and traces of water. In Table 5, we compare the samples analyzed by TGA according to the identified temperature zones.

The weight loss at $250{ }^{\circ} \mathrm{C}$ can be used to estimate the weight percentage of bio-oil that is analyzed by GC/MS, because it is the maximal temperature of the $\mathrm{GC}$ oven. We consider that the area between 250 and $350{ }^{\circ} \mathrm{C}$ corresponds to less volatile compounds. Above $350{ }^{\circ} \mathrm{C}$, pyrolysis phenomena thermally degrade the biooils, resulting in weight loss showed on DTG curves between 350 and $500{ }^{\circ} \mathrm{C}$. Finally, we estimate that the end of the bio-oil distillation (or evaporation behavior) occurs around $500{ }^{\circ} \mathrm{C}$. To give a good estimation of the carbon residue after distillation, the residue is further heated until $900{ }^{\circ} \mathrm{C}$ and then burned in air for $10 \mathrm{~min}$.

The estimation of the carbon residue is given in Table 5 for the five studied bio-oils with a standard deviation obtained for three

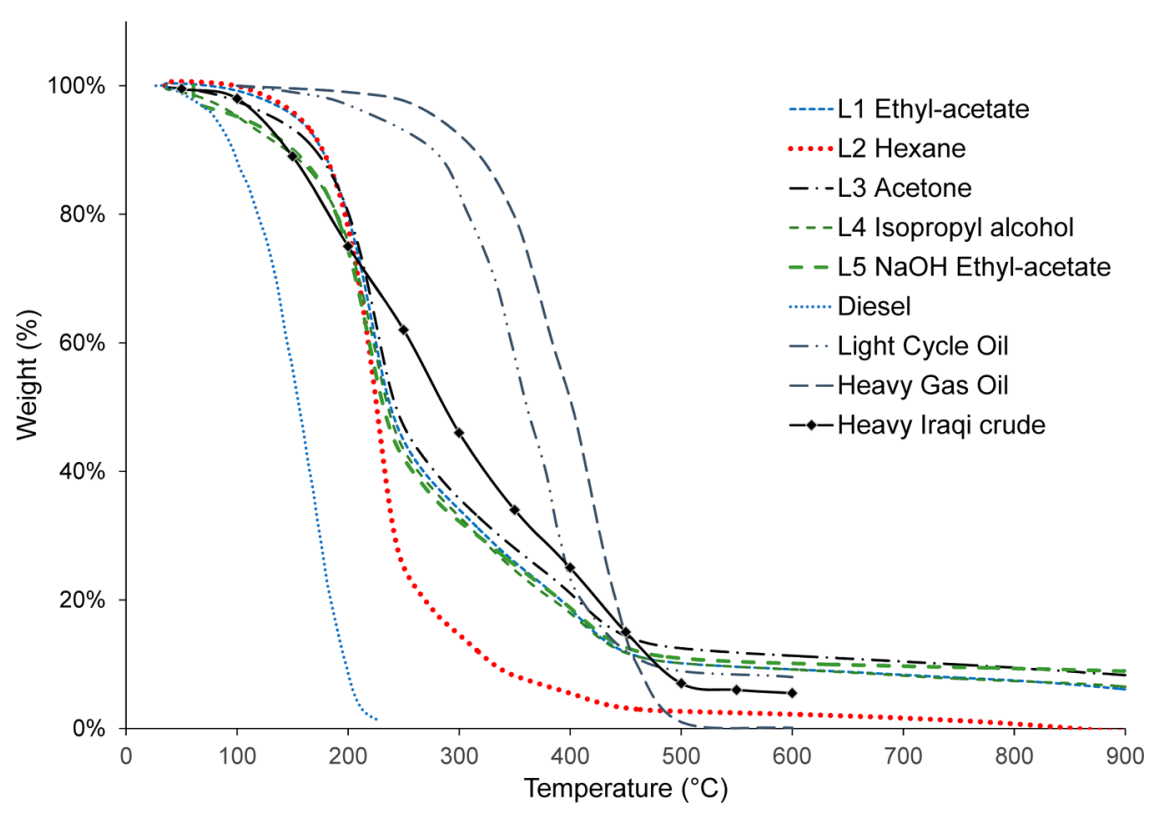

Figure 5. Weight loss curves of bio-oils obtained by different solvents and of some reference fuels. 


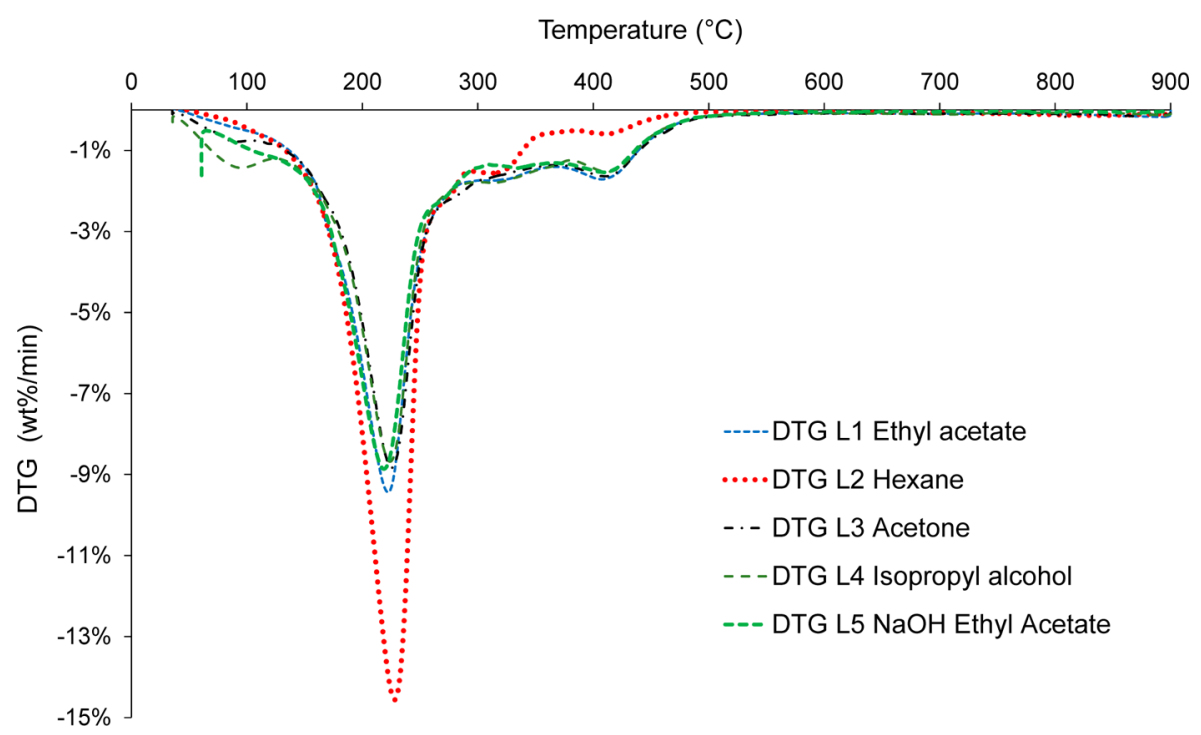

Figure 6. Differentiated weight loss curves for bio-oils obtained by different solvents.

Table 5. Volatility of the Bio-Oils and Residual Carbon in Weight Percentage

\begin{tabular}{|c|c|c|c|c|c|}
\hline$\%$ evaporated & $\mathrm{L} 1$ & $\mathrm{~L} 2$ & L3 & $\mathrm{L} 4$ & L5 \\
\hline $100{ }^{\circ} \mathrm{C}$ & 1 & 0 & 2 & 6 & 5 \\
\hline $100-250{ }^{\circ} \mathrm{C}$ & 56 & 75 & 57 & 58 & 53 \\
\hline $250-350{ }^{\circ} \mathrm{C}$ & 17 & 16 & 16 & 15 & 17 \\
\hline $350-500{ }^{\circ} \mathrm{C}$ & 14 & 5 & 14 & 12 & 14 \\
\hline $250^{\circ} \mathrm{C}$ & 57 & 75 & 59 & 64 & 58 \\
\hline carbon residue & $7.3 \pm 0.6$ & $2.7 \pm 0.6$ & $9.25 \pm 0.01$ & $6.3 \pm 0.6$ & $8 \pm 0.6$ \\
\hline
\end{tabular}

Table 6. Comparison of the Properties of HTL Bio-Oils with Required Values for Commercial Fuels

\begin{tabular}{|c|c|c|c|c|c|}
\hline & gasoline & diesel & biodiesel & heavy marine fuel oil & HTL bio-oil \\
\hline standard & NF EN 590 & NF EN 228 & NF EN 14214 & NF ISO 8217 & \\
\hline density $15^{\circ} \mathrm{C}\left(\mathrm{kg} \cdot \mathrm{m}^{3}\right)$ & $720-775$ & $820-845$ & $860-900$ & $920-1010$ & $960-990$ \\
\hline CCR (wt \%) & $\leq 0.2$ & $\leq 0.3$ & $\leq 0.3$ & $\leq 2.5-20$ & $3-9$ \\
\hline TAN (mg KOH per g bio-oil) & $\leq 0.5$ & $\leq 0.5$ & $\leq 0.5$ & $\leq 2.5$ & $108-159$ \\
\hline iodine value $\left(\mathrm{gI}_{2} / 100 \mathrm{~g}\right.$ bio-oil $)$ & NA & NA & $\leq 120$ & NA & $117-149$ \\
\hline $\mathrm{HHV}\left(\mathrm{MJ} \cdot \mathrm{kg}^{1-}\right)$ & 48 & 45 & $\geq 35$ & NA & $33-38$ \\
\hline water (wt \%) & NA & $\leq 0.02$ & $\leq 0.05$ & $<0.5$ & $<1$ \\
\hline viscosity $(\mathrm{mPa} \cdot \mathrm{s}) @ 40{ }^{\circ} \mathrm{C}$ & $<0.3$ & $3-4$ & $<4$ & $8.5-690$ & 495 \\
\hline
\end{tabular}

analysis repetitions. Carbon residue values confirm that the biooils are rich in heavy structures that have difficulties evaporating. Polar solvents like isopropyl alcohol, acetone, and ethyl acetate extract these complex polar heavy structures, which are not extracted by the use of hexane (nonpolar solvent).

\section{DISCUSSION}

Commercial fuels are subject to a large number of normalized quality criteria. Some of these criteria are presented in Table 6. To date, no precise application is targeted for this type of oil. A general comparison with some common properties and fuels can direct the use of these oils. As can be observed in Table 6, HTL bio-oils are obviously far from commercial quality standards, even for heavy fuel oil. It is however interesting to compare the quality of hydrothermal bio-oils with commercial fuels to evaluate the need for upgrading. Xiu and Shabazi ${ }^{43}$ present different upgrading techniques and the (dis)advantages.

Properties such as TAN and iodine value can be used as indicators. Hydrothermal bio-oils are for instance far too acidic for most applications, even though the oil produced under very basic conditions is somewhat less acidic than oils produced under acidic conditions. It seems that the initial presence of a strong base is not sufficient to guarantee a low acidity of the bio-oil. The work of Hoffman et al., ${ }^{18}$ who present bio-oil from hardwood produced at supercritical conditions, suggests that increasing the temperature of the conversion lowers the acidity of the bio-oil. Wang at al. ${ }^{25}$ showed that the acidity of hydrothermal bio-oils from algae can be reduced significantly by hydrotreatment on a platinum catalyst.

The chemical composition and evaporation behavior appears globally little affected by the conditions under which the bio-oil is produced. This is true for the initial $\mathrm{pH}$ of the mixture, but also for the extraction solvent as long as it remains polar. Changing from a polar solvent to a nonpolar solvent improves the bio-oil quality at the detriment of a lower yield. The high-fiber content of blackcurrant pomace could partially explain these results. Hydrothermal degradation of fibers is responsible for the formation of many oxygenate compounds such as acids, ketones, aldehydes and esters produced by degradation of cellulosic polymers, ${ }^{44}$ as well as phenol derivatives from lignin degrada- 

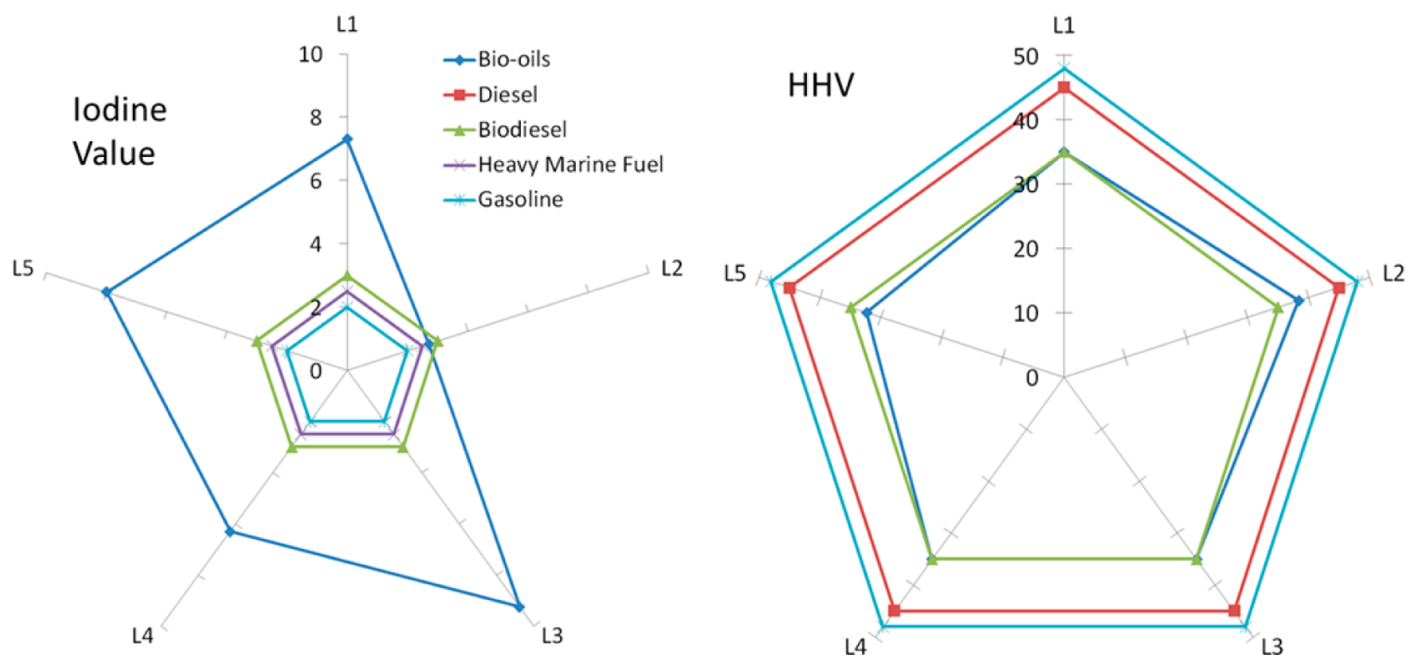

Figure 7. Comparison of hydrothermal bio-oils with commercial fuels in terms of iodine value and HHV.

tion. ${ }^{45}$ It is therefore understandable that polar solvents would be much more efficient to extract those types of molecules.

Figure 7 shows how hydrothermal oils compare to commercial fuels for two different criteria. The best quality oil, produced by hexane extraction (L2), may be applicable as heavy fuel oil for marine applications. Acidity and stability may be a problem and will need to be examined closer. This does not mean that the fuels are inadequate but it does mean that end users may need to adapt their installations and create norms and standards to ensure the compatibility with these fuels.

The comparison with heavy Iraqi crude ${ }^{42}$ presented in section 4.2 is interesting as the evaporation behavior is very similar. It suggests that hydrothermal oils can be considered replacement for crude oils that may interest refineries. In any case, removing the oxygen to create a drop in replacement transport fuel will require some effort.

\section{CONCLUSION}

Hydrothermal liquefaction is capable of producing high heating value bio-oils with interesting yields. These oils are free-flowing but still have an elevated viscosity. The bio-oil extracted with hexane seems to be the best-performing bio-oil compared to biooils extracted with the other three solvents. This bio-oil has the lowest carbon residue, a nearby diesel volatility and a heating value that allows it to replace certain fuels, such as those for marine applications. It should be interesting to test this oil in a low-frequency piston engine.

The main problems with all hydrothermal bio-oils are their acidity and viscosity. Producing bio-oils in basic medium seems to improve the bio-oil quality by lowering its acidity, but this value remains far too important for most existing installations. Some degree of upgrading is consequently necessary to deal with these problems.

Most normalized tests for fuel properties require dedicated equipment and large sample volumes. Some of these techniques can be adapted for characterization of hydrothermal bio-oils at the laboratory scale, which are available in small volumes. It was shown that the applied techniques can yield valuable information about hydrothermal bio-oils. This information can be used to evaluate the bio-oils from a process optimization perspective.

\section{AUTHOR INFORMATION}

\section{Corresponding Author}

*E-mail: geert.haarlemmer@cea.fr. Tel.: 0033438782495. Fax: 0033438785251.

\section{Notes}

The authors declare no competing financial interest.

\section{ACKNOWLEDGMENTS}

The authors would like to acknowledge financial support from the French Research National Agency ANR (LIQHYD project, grant ANR-12-BIME-0003). The authors are also grateful to Julien Roussely, Marine Blanchin, Hélène Miller and Sébastien Thiery for help on the analyses of the products.

\section{ABBREVIATIONS}

$\mathrm{ADF}=$ Acid Detergent Fibers

$\mathrm{ADL}=$ Acid Detergent Lignin

CCR $=$ Conradson Carbon Number

$\mathrm{DM}=$ Dry Matter

DTG = Differential Thermogravimetric

GC/MS = Gas Chromatography coupled with Mass Spectroscopy

$\mathrm{HHV}=$ Higher Heating Value

HTL $=$ Hydrothermal Liquefaction

LHV $=$ Lower Heating Value

NDF $=$ Neutral Detergent Fibers

RON = Research Octane Number

TAN $=$ Total Acid Number

$\mathrm{TG}=$ Thermogravimetric

\section{REFERENCES}

(1) Kirubakaran, V.; Sivaramakrishnan, V.; Nalini, R.; Sekar, T.; Premalatha, M.; Subramanian, P. A review on gasification of biomass. Renewable Sustainable Energy Rev. 2009, 13 (1), 179-186.

(2) Heidenreich, S.; Foscolo, P. U. New concepts in biomass gasification. Prog. Energy Combust. Sci. 2015, 46 (0), 72-95.

(3) Dupont, C.; Commandré, J.-M.; Gauthier, P.; Boissonnet, G.; Salvador, S.; Schweich, D. Biomass pyrolysis experiments in an analytical entrained flow reactor between 1073 and 1273 K. Fuel 2008, 87 (7), 1155-1164.

(4) Mohan, D.; Pittman, C. U.; Steele, P. H. Pyrolysis of Wood/ Biomass for Bio-oil: A Critical Review. Energy Fuels 2006, 20 (3), 848889. 
(5) Bridgwater, A. V. Review of fast pyrolysis of biomass and product upgrading. Biomass Bioenergy 2012, 38 (0), 68-94.

(6) Kruse, A.; Dahmen, N. Water - A magic solvent for biomass conversion. J. Supercrit. Fluids 2015, 96 (0), 36-45.

(7) Kruse, A.; Funke, A.; Titirici, M.-M. Hydrothermal conversion of biomass to fuels and energetic materials. Curr. Opin. Chem. Biol. 2013, 17, 515-521.

(8) Peterson, A. A.; Vogel, F.; Lachance, R. P.; Fröling, M.; Antal, M. J.; Tester, J. a. J. W. Thermochemical biofuel production in hydrothermal media: A review of sub- and supercritical water technologies. Energy Environ. Sci. 2008, 1 (1), 32-65.

(9) Tekin, K.; Karagöz, S.; Bektaş, S. A review of hydrothermal biomass processing. Renewable Sustainable Energy Rev. 2014, 40, 673-687.

(10) Haarlemmer, G. Simulation study of improved biomass drying efficiency for biomass gasification plants by integration of the water gas shift section in the drying process. Biomass Bioenergy 2015, 81 (10), 129-136.

(11) Déniel, M.; Haarlemmer, G.; Roubaud, A.; Weiss-Hortala, E.; Fages, J. Energy valorisation of food processing residues and model compounds by hydrothermal liquefaction. Renewable Sustainable Energy Rev. 2016, 54, 1632-1652.

(12) Toor, S. S.; Rosendahl, L.; Rudolf, A. Hydrothermal liquefaction of biomass: A review of subcritical water technologies. Energy 2011, 36 (5), 2328-2342.

(13) Vardon, D. R.; Sharma, B. K.; Scott, J.; Yu, G.; Wang, Z.; Schideman, L.; Zhang, Y.; Strathmann, T. J. Chemical properties of biocrude oil from the hydrothermal liquefaction of Spirulina algae, swine manure, and digested anaerobic sludge. Bioresour. Technol. 2011, 102, $8295-8303$.

(14) Huang, H.-j.; Yuan, X.-z. Recent progress in the direct liquefaction of typical biomass. Prog. Energy Combust. Sci. 2015, 49, 59-80.

(15) Ramos-Tercero, E. A.; Bertucco, A.; Brilman, D. W. F. Process Water Recycle in Hydrothermal Liquefaction of Microalgae To Enhance Bio-oil Yield. Energy Fuels 2015, 29 (4), 2422-2430.

(16) Zhu, Z.; Rosendahl, L.; Toor, S. S.; Yu, D.; Chen, G. Hydrothermal liquefaction of barley straw to bio-crude oil: Effects of reaction temperature and aqueous phase recirculation. Appl. Energy 2015, 137, 183-192.

(17) Yin, S.; Dolan, R.; Harris, M.; Tan, Z. Subcritical hydrothermal liquefaction of cattle manure to bio-oil: Effects of conversion parameters on bio-oil yield and characterization of bio-oil. Bioresour. Technol. 2010, $101(10), 3657-3664$.

(18) Hoffmann, J.; Jensen, C. U.; Rosendahl, L. A. Co-processing potential of HTL bio-crude at petroleum refineries - Part 1: Fractional distillation and characterization. Fuel 2016, 165, 526.

(19) Gan, J.; Yuan, W. Operating condition optimization of corncob hydrothermal conversion for bio-oil production. Appl. Energy 2012, 103, $350-357$.

(20) Minowa, T.; Kondo, T.; Sudirjo, S. T. Thermochemical liquefaction of indonesian biomass residues. Biomass Bioenergy 1998, 14 (5-6), 517-524.

(21) Mørup, A. J.; Becker, J.; Christensen, P. S.; Houlberg, K.; Lappa, E.; Klemmer, M.; Madsen, R. B.; Glasius, M.; Iversen, B. B. Construction and Commissioning of a Continuous Reactor for Hydrothermal Liquefaction. Ind. Eng. Chem. Res. 2015, 54 (22), 5935-5947.

(22) Villadsen, S. R.; Dithmer, L.; Forsberg, R.; Becker, J.; Rudolf, A.; Iversen, S. B.; Iversen, B. B.; Glasius, M. Development and Application of Chemical Analysis Methods for Investigation of Bio-Oils and Aqueous Phase from Hydrothermal Liquefaction of Biomass. Energy Fuels 2012, 26 (11), 6988-6998.

(23) Valdez, P. J.; Dickinson, J. G.; Savage, P. E. Characterization of Product Fractions from Hydrothermal Liquefaction of Nannochloropsis sp. and the Influence of Solvents. Energy Fuels 2011, 25 (7), 3235-3243.

(24) Kumar, D.; Pant, K. K. Production and characterization of biocrude and biochar obtained from non-edible de-oiled seed cakes hydrothermal conversion. J. Anal. Appl. Pyrolysis 2015, 115, 77-86.

(25) Wang, Z.; Adhikari, S.; Valdez, P.; Shakya, R.; Laird, C. Upgrading of hydrothermal liquefaction biocrude from algae grown in municipal wastewater. Fuel Process. Technol. 2016, 142, 147-156.
(26) Pavlovič, I.; Knez, Ž.; Škerget, M. Hydrothermal Reactions of Agricultural and Food Processing Wastes in Sub- and Supercritical Water: A Review of Fundamentals, Mechanisms, and State of Research. J. Agric. Food Chem. 2013, 61 (34), 8003-8025.

(27) Yuan, X.; Wang, J.; Zeng, G.; Huang, H.; Pei, X.; Li, H.; Liu, Z.; Cong, M. Comparative studies of thermochemical liquefaction characteristics of microalgae using different organic solvents. Energy 2011, 36 (11), 6406-6412.

(28) Singh, R.; Bhaskar, T.; Balagurumurthy, B. Effect of solvent on the hydrothermal liquefaction of macro algae Ulva fasciata. Process Saf. Environ. Prot. 2015, 93, 154-160.

(29) Mazaheri, H.; Lee, K. T.; Bhatia, S.; Mohamed, A. R. Sub/ supercritical liquefaction of oil palm fruit press fiber for the production of bio-oil: Effect of solvents. Bioresour. Technol. 2010, 101 (19), 76417647.

(30) Yang, X.; Lyu, H.; Chen, K.; Zhu, X.; Zhang, S.; Chen, J. Selective extraction of bio-oil from hydrothermal liquefaction of Salix psammophila by organic solvents with different polarities through multistep extraction separation. BioResources 2014, 9 (3), 5119-5233.

(31) Ou, L.; Thilakaratne, R.; Brown, R. C.; Wright, M. M. Technoeconomic analysis of transportation fuels from defatted microalgae via hydrothermal liquefaction and hydroprocessing. Biomass Bioenergy 2015, $72(0), 45-54$.

(32) Oasmaa, A.; van de Beld, B.; Saari, P.; Elliott, D. C.; Solantausta, Y. Norms, Standards, and Legislation for Fast Pyrolysis Bio-oils from Lignocellulosic Biomass. Energy Fuels 2015, 29 (4), 2471-2484.

(33) Wang, F.; Chang, Z.; Duan, P.; Yan, W.; Xu, Y.; Zhang, L.; Miao, J.; Fan, Y. Hydrothermal liquefaction of Litsea cubeba seed to produce bio-oils. Bioresour. Technol. 2013, 149 (0), 509-515.

(34) Collura, S.; Azambre, B.; Weber, J.-V. Thermal behaviour of Miscanthus grasses, an alternative biological fuel. Environ. Chem. Lett. 2005, 3, 95-99.

(35) Gautam, A.; Agarwal, A. K. Determination of important biodiesel properties based on fuel temperature correlations for application in a locomotive engine. Fuel 2015, 142, 289-302.

(36) Ghetti, P. A rapid heating TGA method for evaluating the carbon residue of fuel oil. Fuel 1994, 73 (12), 1918.

(37) Elliott, D. C.; Schiefelbein, G. F. Liquid Hydrocarbon fuels from biomass. American Chemical Society, Division of Fuel Chemistry Annual Meeting Preprints; American Chemical Society: 1989; Vol. 34, pp 11601166.

(38) Oasmaa, A.; Elliott, C. D.; Korhonen, J. Acidity of Biomass Fast Pyrolysis Bio-oils. Energy Fuels 2010, 24, 6548-6554.

(39) Bowler, R. G. A simple titration method for determining the specific gravity on one drop of urine. J. Clin. Pathol. 1951, 4, 491-495.

(40) Hashimoto, N.; Nomura, H.; Suzuki, M.; Matsumoto, T.; Nishida, H.; Ozawa, Y. Evaporation characteristics of a palm methyl ester droplet at high ambient temperatures. Fuel 2015, 143, 202-210.

(41) Gonçalves, M. L. A.; Ribeiro, D. A.; da Mota, D. A. P.; Teixeira, A. M. R. F.; Teixeira, M. A. G. Investigation of petroleum medium fractions and distillation residues from Brazilian crude oils by thermogravimetry. Fuel 2006, 85 (7-8), 1151-1155.

(42) García Barneto, A.; Carmona, J. A.; Barrón, A. Thermogravimetric Monitoring of Crude Oil and Its Cuts in an Oil Refinery. Energy Fuels 2015, 29 (4), 2250-2260.

(43) Xiu, S.; Shahbazi, A. Bio-oil production and upgrading research: A review. Renewable Sustainable Energy Rev. 2012, 16 (7), 4406-4414.

(44) Yin, S.; Tan, Z. Hydrothermal liquefaction of cellulose to bio-oil under acidic, neutral and alkaline conditions. Appl. Energy 2012, 92, 234-239.

(45) Kang, S.; Li, X.; Fan, J.; Chang, J. Hydrothermal conversion of lignin: A review. Renewable Sustainable Energy Rev. 2013, 27, 546-558. 